\title{
Observed and Interpolated Precipitation Trends and Variability in the Yangtze Catchment Area*
}

\author{
Stefan BECKER ${ }^{1}$, Marco GEMMER ${ }^{2} \&$ JIANG Tong ${ }^{3}$ \\ (1:Department of Geography, Justus Liebig University, Giessen, Germany;2:Centre for international Development and Environmental \\ Research, Justus Liebig University, Giessen, Germany; 3:Nanjing Institute of Geography and Limnology, CAS,Nanjing \\ 210008,P.R.,China)
}

Abstract Precipitation trends in China with special emphasis on the Yangtze catchment area have been analysed. Significant positive and negative trends for the second half of last century have been detected for different regions on a monthly scale. The interpolation of the trends lead to characteristic spatial trend patterns in China. The analysis of long-term precipitation records in the Yangtze catchment area revealed a concentration of summer precipitation within a shorter period of time on the monthly scale and a distinct cyclicity for some stations on the annual scale.

Keywords: China, Yangtze River, climate change, precipitation trend analysis

The implications of precipitation variations are particularly relevant for China as to it's regional disparities of natural resources. Climate variations can increase the frequency of droughts and floods due to the unequal availability of water. The most recent example is the higher number of floods in the Yangtze River catchment in the 1990s and the water shortage in the Yellow river catchment which, of course, have been aggravated by human activities. Therefore, the evaluation of precipitation variations are important for the assessment of climate induced risks and countermeasures. Analyses of precipitation trends in China have also been published e.g. by Chen and others ${ }^{[1-7]}$.

\section{Data and methods}

The evaluations are based on two data sets: The first one consists of data of 160 National Meteorological Observatory stations with long-term monthly precipitation data sets which are spread widely over China. The data sets, which have been provided by the National Climatic Center of the China Meteorological Administration (CMA), contain monthly values from January 1951 to December 2002. The density of stations is naturally lower in the sparsely populated high mountainous and desert area of west and north-west China.

The second data set consists of the data of 16 stations with long-term precipitation data which

\footnotetext{
* Supported by the Key project of Knowledge Creativity Engineering, Chinese Academy of Sciences (KZCX3-SW-331), National Natural Science Foundation of China (Grant No. 40271112).

Received:2003-08-01;Accepted:2003-11-23. Stefan BECKER, male, Ph.D, email: Stefan .Becker @ geogr.uni-giessen.de.
} 
are spread widely over the Yangtze river catchment. Data of the Yangtze source area are unfortunately not available for the first half of the 20th century. The data set contains monthly precipitation values with time series starting in Shanghai e.g. in 1872.

A general quality assurance review of the data by checking them for completeness, reasonableness, and accuracy was undertaken and the station data were individually tested and visually inspected for the presence of spurious trends and jumps.

The prerequisite for time series analysis is the homogeneity of the precipitation records which was analysed by calculating various procedures like the von Neumann ratio $(\mathrm{N})$, the cumulative deviations $\left(\mathrm{Q} / \mathrm{n}^{-0.5}\right.$ and $\left.\mathrm{R} / \mathrm{n}^{-0.5}\right)$, and the Bayesian procedures ( $\mathrm{U}$ and $\left.\mathrm{A}\right)$. The data sets of most stations proved to be homogeneous with a significance beyond the $95 \%$ confidence level according to most criteria.

Inter- and inner-annual variabilities, and decadal fluctuations have been assessed and linear trend analysis as well as the Mann-Kendall trend test have been applied to evaluate precipitation changes or trends. Confidence levels of $90 \%, 95 \%$, and $99 \%$ were taken as thresholds to classify the significance of positive and negative precipitation trends. Trends at a significance below the $90 \%$ confidence level were not considered.

The observed trends were spatially interpolated by applying the Inverse Distance Weighted (IDW) interpolation method which implies that each station has a local influence that decreases with distance. A number of 4 neighbouring stations has been used to quantify the significance of trends for each raster cell. The power parameter in the IDW interpolation which controls the significance of the neighbouring stations upon the interpolated significance of trends was set to 6 . The choice of the relatively high power ensures a high degree of local influence and giving the output surface increased detail.

\section{Observed precipitation trends}

Figures $1 \mathrm{a}$ and $1 \mathrm{~b}$ show the relative frequency of precipitation trends for each month as percentage of the 160 stations. The results are based on the Mann-Kendall-Test which was applied to the data from 1951 to 2002 . Trends were differentiated according to their significance at 90 , 95, and $99 \%$ confidence levels.

Both, positive and negative precipitation trends on all confidence levels exist in parallel at each month. January, July, September, and November are the months which show the highest number of trends in both directions whereas the smallest number can be noted for March, October, and December.

Comparatively many positive trends - which means increase in rainfall - can be noted in January, June, and July. Many negative trends prevail in February, September, and November. A relatively equal number of stations with both positive and negative trends can be detected in August, October, and December. 


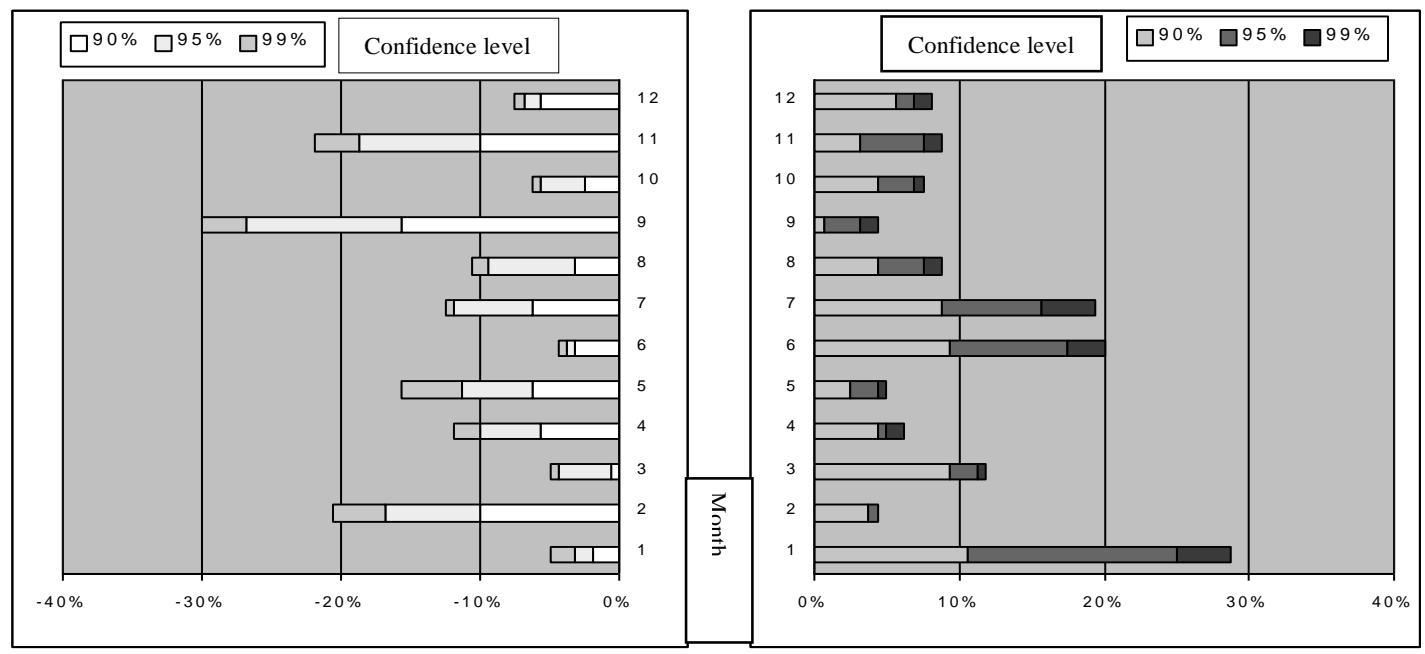

Fig. 1 Relative monthly frequency of negative (left graph) and positive (right graph) precipitation trends as percentage of the 160 stations

Figures $2 \mathrm{a}-2 \mathrm{~d}$ display examples of significant positive and negative precipitation trends at four stations in January and July to clarify the order of magnitude of the investigated trends. The graphs show the monthly precipitation sums 1951-2002 (grey line) and the attached linear trends (black line). The $r^{2}$ values show that a maximum of $18 \%$ of the variation can be explained by the linear regression. The increase of precipitation over the last 51 years reaches values beyond $150 \%$ of the base level.
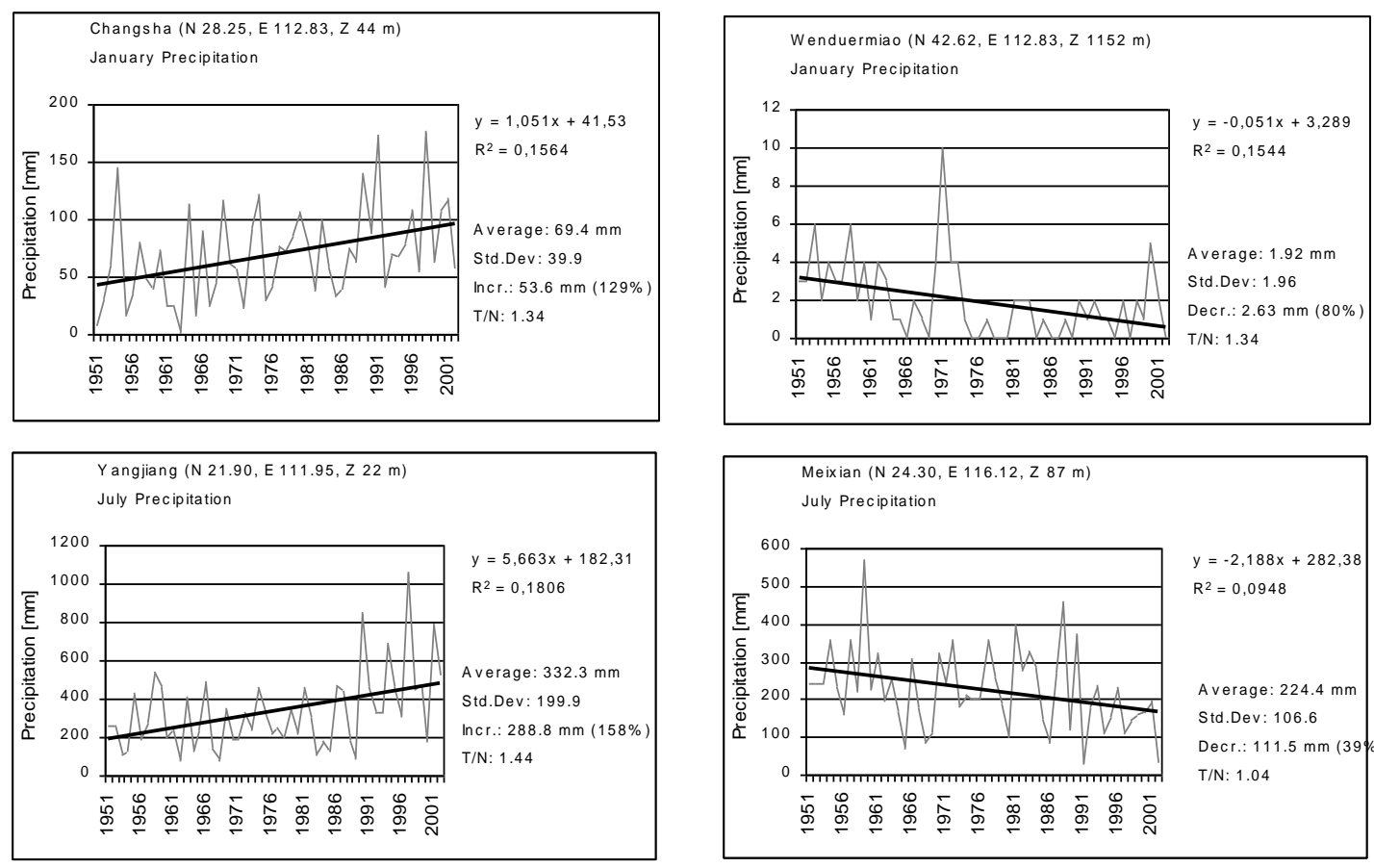

Fig. 2 Examples of precipitation trends which are significant beyond the $99 \%$ confidence levels 


\section{Spatial interpolations of precipitation trends}

Figures $3 \mathrm{a}$ and $3 \mathrm{~b}$ show the interpolated January and July precipitation trends for China from 1951-2002. The displayed classes are based on the confidence levels, which were introduced above. An agglomeration of stations with significant trends or trend belts give a strong indication that this trend is actually characteristic for this particular region whereas isolated stations may not justify this statement.

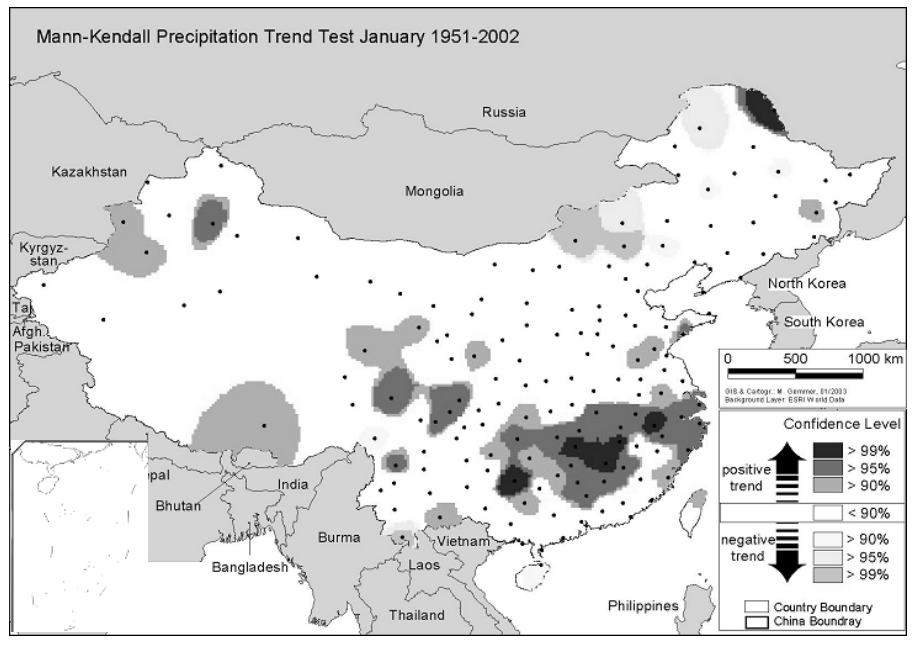

Fig.3a Interpolated January precipitation trends in China

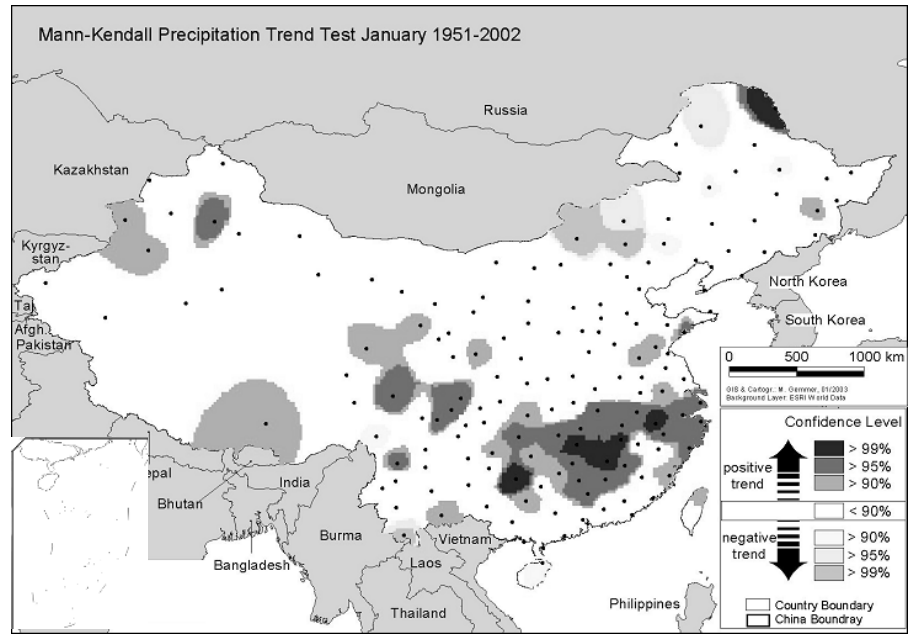

Fig. 3b Interpolated July precipitation trends in China

The January map reveals that the relatively high number of positive trends mainly refers to stations which are concentrated in a belt which covers the middle and lower Yangtze river catchment as well as Dongting and Poyang lake catchments. These stations are mainly located in the lowlands and the foothills of the adjoining mountain ranges. Another agglomeration of positive precipitation trends is located in the highlands of Sichuan and Qinghai provinces. 
Precipitation trend patterns in July follow the three topographical features of China. Whereas large parts of the south-east Lowlands and the western mountainous regions are dominated by positive trends we observe negative trends along the transition zone of the middle ranged mountain axis from central to north-east China.

\section{Precipitation trends in the Yangtze catchment}

Figure $4 \mathrm{a}$ and $4 \mathrm{~b}$ show examples of annual precipitation and low-pass filtered data (left graphs) and high-pass filtered data and absolute decadal means (right graphs).
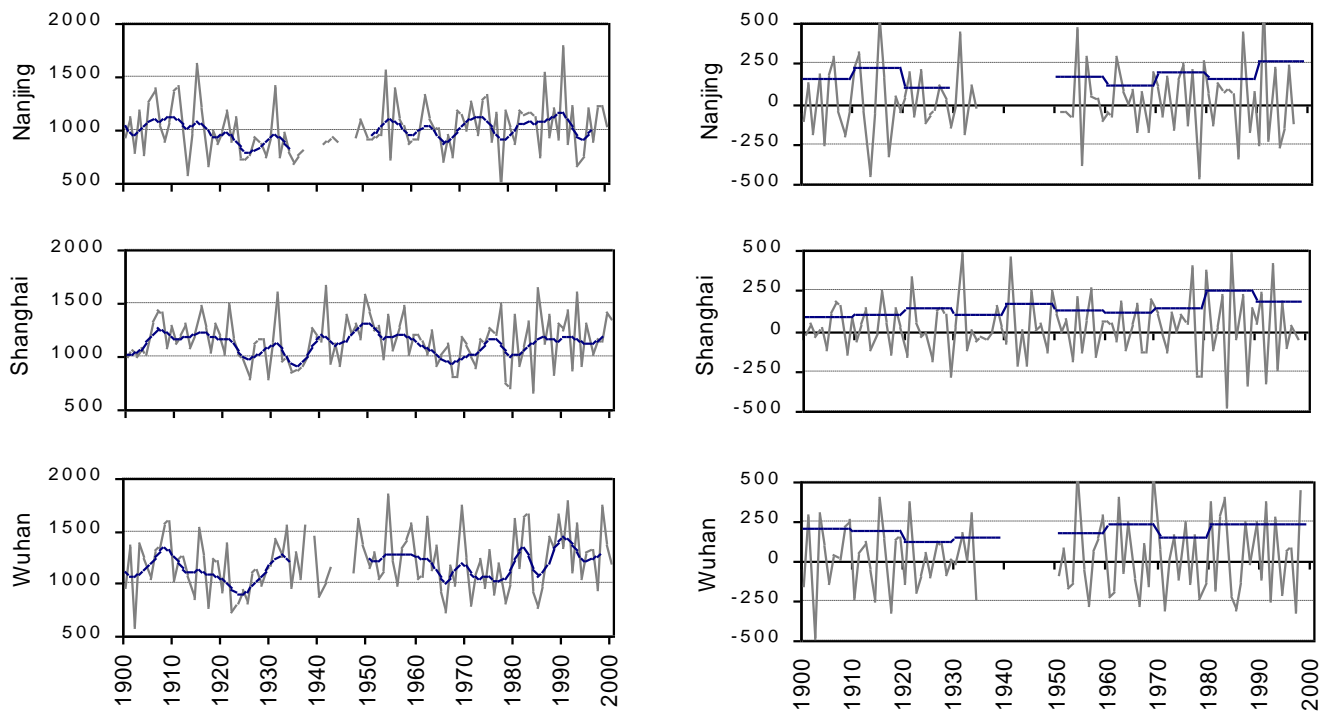

Fig. 4 Left: Annual Precipitation (mm, original and low-pass filtered data), Right: Annual Precipitation (mm,

high-pass filtered data and absolute decadal means)

No general increase or trend of the annual precipitation and its variability in the Yangtze river catchment has been detected. Decadal-scale fluctuations of precipitation are apparent for the whole time series. The 1990s were no exceptionally wet decade concerning annual precipitation in the context of 20th century.

The monthly analysis of long term precipitation trends and decadal scale fluctuation in the Yangtze catchment reveals the fact that most of the previous decades show higher amounts of rainfall during May and August and lower amounts during June and July. This can also be seen from Fig. 5, which shows the confidence level of precipitation trends in the summer months. The maps are based on the gridded precipitation data from 1050 - 1999. The lighter shades indicate negative trends (decreased precipitation) whereas the darker shade indicate positive trends (increased precipitation). Significant positive trends for the summer months with precipitation maximum in the Yangtze Catchment are often preceded and/or followed by significant negative trends in the earlier and/or later months. This is a strong indication for the tendency towards a concentration of summer rainfall within a shorter period of time. 


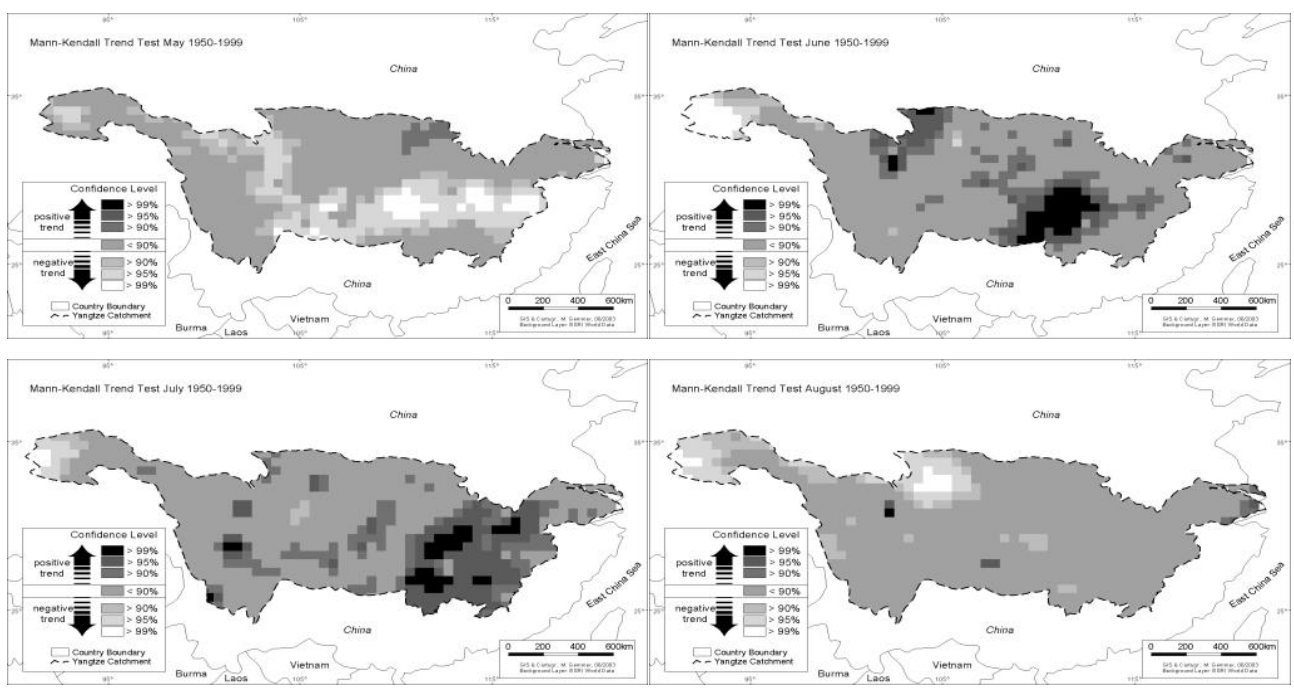

Fig. 5 Gridded precipitation trends for the months May - August (the shades indicate the confidence levels of positive and negative trends)

\section{Harmonic analysis of the annual precipitation}

Precipitation time series in the Yangtze catchment over a long period of time unveil a regular pattern after applying smoothing procedures like moving averages or low-pass filtering. This can be seen at the examples of annual precipitation values in Wuhan and Shanghai (Fig. 6), where, instead of a trend, we rather find distinct cycles. The identification of the underlying cyclicity was achieved by a harmonic analysis. The Fourier analysis reveals very distinct harmonic patterns for the annual precipitation sums which is demonstrated by the high correlation between the 5-year moving averages and the harmonic wave obtained by Fourier analysis.

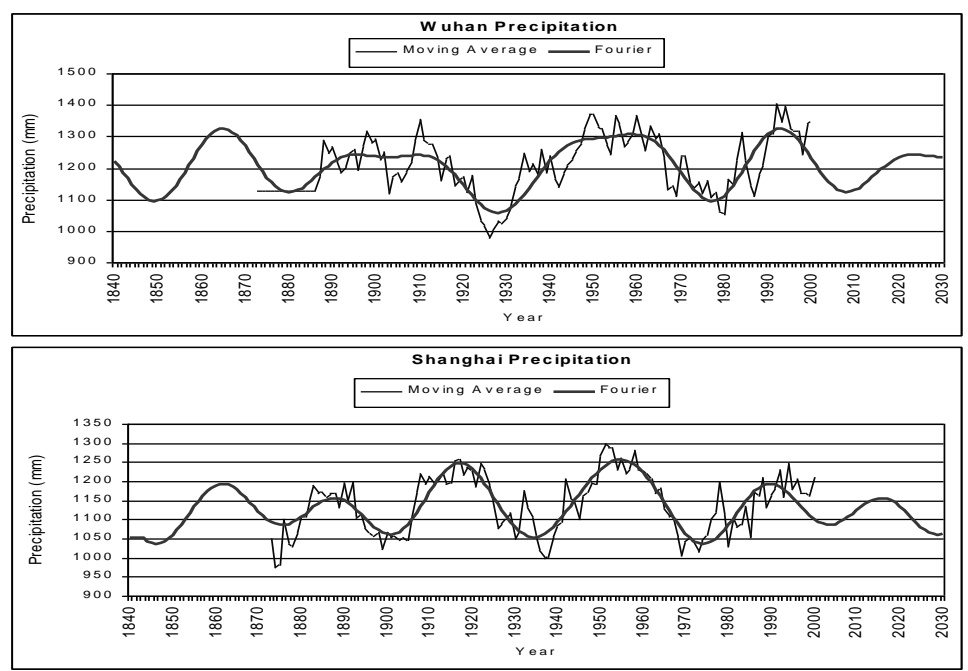

Fig. 6 Low pass filtered annual precipitation in Wuhan and Shanghai and harmonic waves

(obtained by Fourier analysis) 
The cycles do not necessarily show a constant frequency, meaning that the periods take on different lengths, for example the periods in Shanghai vary in the region of 30-40 years. Although we have no available records we would expect another crest in the 1860s and the stations should face a decrease of annual precipitation within the next years followed by an increase in 8 to 10 years.

\section{Conclusion and outlook}

The increase of flood disasters in the Yangtze River catchment area cannot be directly related to precipitation trends on an annual scale. However, precipitation trends in China are detectable on a monthly scale and they show a characteristic spatial pattern. The data give reason for the hypothesis of a concentration of summer precipitation in the Yangtze catchment area towards the end of last century. The analysis of daily precipitation records will be necessary to verify this hypothesis, which would back up the hypothesis of an aggravation of flood risks due to climate change. Predictions for future precipitation scenarios based on smoothed data sets can be achieved by harmonic analyses. A better temporal resolution and the forecast of extreme events is expected to be achieved by neural network analysis.

\section{References}

1 Chen J y. Analysis and Prediction of the Causes to the 1998 Flood in China. Natural Disaster Reduction in China ,1999, (8) 3:98-106

2 CNC-IGBP. Advances in Global Change Studies of China. Beijing: Ocean Press, 1998

3 Dai A, I Y Fung, A D Del Genio. Surface observed Land Precipitation Variations during 1900-1988. Journal of Climate, 1997, 10: $2943-2962$.

4 Domroes M. Raeumliche und zeitliche Variablitaet der Sommerniederschlaege in China (In German). Geographische Rundschau, 2001,53 (10): 36-41

5 Gong D Y, S W Wang. Severe summer rainfall in China associated with enhanced global warming. Climatic Research, 2000, 16: $51-59$

6 Jiang J, D Zhang, K Fraedrich. Historic Climate Variability of Wetness in east China (960-1992) A Wavelet Analysis. International Journal of Climatology, 1997, 17: 969-971

7 Zhu J H, S W Wang. 80a-Oscillation of Summer Rainfall over the East Part of China and East-Asian Summer Monsoon. Advances in Atmospheric Sciences, 2001, (18) 5: 1044-1051 


\title{
长江流域降水变化及其趋势演变
}

\author{
Stefan BECKER ${ }^{1}$, Marco GEMMER $^{2}$ \& 姜 制 ${ }^{3}$ \\ (1:Department of Geography, Justus Liebig University, Giessen, Germany; \\ 2:Centre for international Development and Environmental Research, Justus Liebig University, Giessen, Germany; \\ 3: 中国科学院南京地理与湖泊研究所, 南京 210008)
}

摘 要

本文对中国长江流域降水趋势进行了分析. 指出对月降水量而言, 20 世纪后 50 年不同区域出现不同 的降水趋势变化特征. 趋势插补法研究表明中国降水时空分布趋势十分明显. 对长江流域长期降水资料分 析研究指出夏季月份降水时间更集中，而对年降水而言在一些站则表现出明显的周期变化.

关键词 中国长江 气候变化 降水趋势分析

分类号 P467 P333 